УДК 517.9

\title{
Noise-induced Chemical Chaos. Basic Kinetic Model and its Parametric Analysis
}

\author{
Svetlana B. Tsybenova \\ Valeriy I. Bykov* \\ Luidmila S. Trotsenko \\ Emanuel Institute of Biochemical Physics RAS \\ Kosygin St., 4, Moscow, 119334 \\ Siberian Federal University \\ Svobodnyi, 79, Krasnoyarsk, 660041
}

Russia

Received 20.06.2018, received in revised form 26.07.2018, accepted 01.08.2018

The basic model of non-stationary behaviour of a catalytic system is proposed. Parameters range is determined wherein oscillations are observed. It is shown that when parameters exceed the range small fluctuations of parameters can lead to the chaotization of system dynamics as a whole.

Keywords: chemical kinetics, kinetic model, bifurcation, noise, chaos, parametric analysis. DOI: $10.17516 / 1997-1397-2018-11-5-1-5-644-648$

\section{Introduction}

At present it is known that behaviour of chemical systems in a kinetic region can be quite complex (see e.g. [1-5]). In this paper we present a rather simple kinetic model which corresponds to a catalytic scheme of transformations under condition of small fluctuations of model parameters. Numerical results show that near the critical conditions (multiplicity of steady states and oscillations) can appear complex oscillations that are chaotic in character. Here we understand chaos as complex behaviour of dynamical system in time for small fluctuations of parameters.

Let us consider the following scheme of catalytic transformations

$$
\begin{aligned}
& \text { 1) } A+Z \rightleftarrows X, \\
& \text { 2) } X+2 Z \rightarrow 3 Z+B, \\
& \text { 3) } B+Z \rightleftarrows Y,
\end{aligned}
$$

where $Z$ is the active site on the catalytic surface. $A$ and $B$ are substances in the gas phase $(A$ and $B$ are adsorbed on $Z$, and form $X$ and $Y$ ). The main non linearity is in the second stage that is autocatalytic in character. Stage 3 ) is a buffer stage. It is well known that kinetic model corresponding to (1) can have multiple steady states and oscillations even if $A, B=$ const $[1,2,4]$.

The oscillator is a more realistic scheme of transformations. For example, let us consider the

*vibykov@mail.ru

(c) Siberian Federal University. All rights reserved 
following kinetic model $[2,3]$
1) $\mathrm{O}_{2}+2 \mathrm{Pt} \rightleftarrows 2 \mathrm{PtO}$,
2) $\mathrm{CO}+\mathrm{Pt} \rightleftarrows \mathrm{PtCO}$,
3) $\mathrm{PtCO}+\mathrm{PtO} \rightarrow 2 \mathrm{Pt}+\mathrm{CO}_{2}$,
4) $\mathrm{CO}+\mathrm{Pt} \rightleftarrows(\mathrm{PtCO})^{*}$,

where the buffer substance $(P t C O)^{*}$ is the tightly bound form of $C O$ adsorption on the platinum surface.

Together with (2) there is another kinetic model of catalytic hydrogen oxidation

$$
\begin{aligned}
& \text { 1) } \mathrm{H}_{2}+\mathrm{Pt} \rightleftarrows \mathrm{PtH}, \\
& \text { 2) } \mathrm{O}_{2}+2 \mathrm{Pt} \rightleftarrows 2 \mathrm{PtO}, \\
& \text { 3) } \mathrm{PtH}_{2}+\mathrm{PtO} \rightarrow 2 \mathrm{Pt}+\mathrm{H}_{2} \mathrm{O} .
\end{aligned}
$$

The basic kinetic model that corresponds to scheme (3) is a trigger, that is, it is a system with three steady states, two of which are stable and the third is unstable. When parameters are changed (e.g., partial pressures of reactants $\mathrm{O}_{2}, \mathrm{CO}$ or $\mathrm{H}_{2}$ ) the kinetic model can have multiple steady states or oscillations $[1,2]$.

Let us write the basic kinetic model that corresponds to non-linear scheme of transformations (1) in the form

$$
\begin{aligned}
& \frac{d z}{d t}=-k_{1} a z+k_{-1} x+k_{2} x z^{2}-k_{3} z+k_{3} y \\
& \frac{d y}{d t}=k_{3} b z-k_{-3} y
\end{aligned}
$$

where $x$ is the dimensionless concentration (or the cover degree of the catalyst $Z$ by the substance $A$ from the gas phase). $y$ is the dimensionless concentration of the adsorbed substance $B$. Parameters $a$ and $b$ are constants that correspond to concentrations of $A$ and $B$. According to the law of conservation of mass, we have

$$
x+y+z=1 .
$$

Steady states of dynamic model (4) are determined from the following relations

$$
\begin{aligned}
& -k_{1} a z+k_{-1} x+k_{2} x z^{2}-k_{3} z+k_{3} y=0, \\
& k_{3} b z-k_{-3} y=0 .
\end{aligned}
$$

Values of $x, y$ and $z$ in a steady state are determined from relations (5) - (7) in the form

$$
\begin{aligned}
-k_{1} a z & +k_{-1}(1-\alpha z)+k_{2} z^{2}(1-\alpha z)=0, \\
y & =\frac{k_{3} b}{k_{-3}} z, \\
x & =1-y-z .
\end{aligned}
$$

For given values of parameters $k_{1}, k_{-1}, \alpha=k_{3} / k_{-3}, k_{2}, k_{3}$ and $k_{-3}$ cubic equation (8) is solved with respect to $z$. Further, stationary values of concentrations $y$ and $x$ are calculated from (9) 
and (10).Parameters $k_{1}, k_{-1}$ and $k_{2}$ can be obtained from (8):

$$
\begin{aligned}
k_{1}(z) & =\frac{(1-\alpha z)\left(k_{-1}+k_{2} z^{2}\right)}{a z}, \\
k_{-1}(z) & =\frac{k_{1} a z-k_{2} z^{2}(1-\alpha z)}{1-\alpha z}, \\
k_{2}(z) & =\frac{k_{1} a z-k_{-1}(1-\alpha z)}{z^{2}(1-\alpha z)},
\end{aligned}
$$

where $\alpha=k_{3} b / k_{-3}$. An example of parametric relationship (11) is given in Fig. 1 for the following set of parameters: $k_{1}=0.08, k_{-1}=0.001, k_{2}=1, k_{3}=0.0032, k_{-3}=0.002, a=1, b=1$.

Thus, dynamic system (4) can have one or three steady states. The stability of these steady states is defined by the roots of characteristic equation

$$
\lambda^{2}-\sigma \lambda+\Delta=0
$$

where $\sigma=a_{11}+a_{22}$ is the trace of the Jacobian matrix for the right hand side of dynamic system (4). $\Delta=a_{11} a_{22}-a_{12} a_{21}$ is the determinant of the Jacobian matrix. A detailed analysis of the critical conditions for (12) is not considered here. We are only interested in the case of unique and unstable steady state, i.e., in the case of existence of undamped oscillations in dynamic system (4) .

Elements of the Jacobian matrix for the right hand side of dynamic system (4) are

$$
\begin{aligned}
& a_{11}=-k_{1} a-k_{-1}-k_{2} z^{2}+2 k_{2} x z-k_{3} b, \\
& a_{12}=-k_{-1}-k_{2} z^{2}+k_{-3}, \\
& a_{21}=k_{3} b \\
& a_{22}=-k_{-3} .
\end{aligned}
$$

The conditions $\sigma=0$ and $\Delta=0$ set ranges of parameters. As parameters change, the number and stability of steady states of dynamic model (4) change [1,2]. An example of of multiplicity curve $L_{\Delta}(\Delta=0)$ and neutrality curve $L_{\sigma}(\sigma=0)$ are shown in Fig. 2. The mutual arrangement of these curves define the number and stability of steady states of kinetic model (4).

There are two points inside the neutrality region defined by the curve $L_{\sigma}$ (see Fig. 2). Point 1 corresponds to such combination of parameters wherein oscillating solutions exist. They are stable for small variations of parameters (see Fig. 3). Point 2 in Fig. 2 corresponds to such combination of parameters that it is close to the border of the region wherein oscillating solutions exist. For this combination of parameters even small external noise (small random change of parameter a) can lead to complex oscillations having the character of "chaos" (see Fig. 4).

Note that near the boundary of multiplicity region (curve $L_{\Delta}$ ) and stability region (curve $L_{\sigma}$ ) the high parametric sensitivity of solutions of model (4) is observed. For example, for a small change in parameters the only and stable steady state solution can lose stability. It results in occurrence of oscillating solutions (Fig. 3).

Numerical analysis shows that chaotization of solutions of kinetic model (4) occurs for small fluctuations of parameters of system (4) (for example, parameter $a$ ) (see Fig. 4). Due to the high sensitivity of oscillating solutions for even small fluctuations of parameters the chaotization of system dynamic is observed.

The simplest (basic) model of non-stationary behaviour of the catalytic system is proposed in the paper. It is shown that near the boundary of parameter region where oscillations exist, 


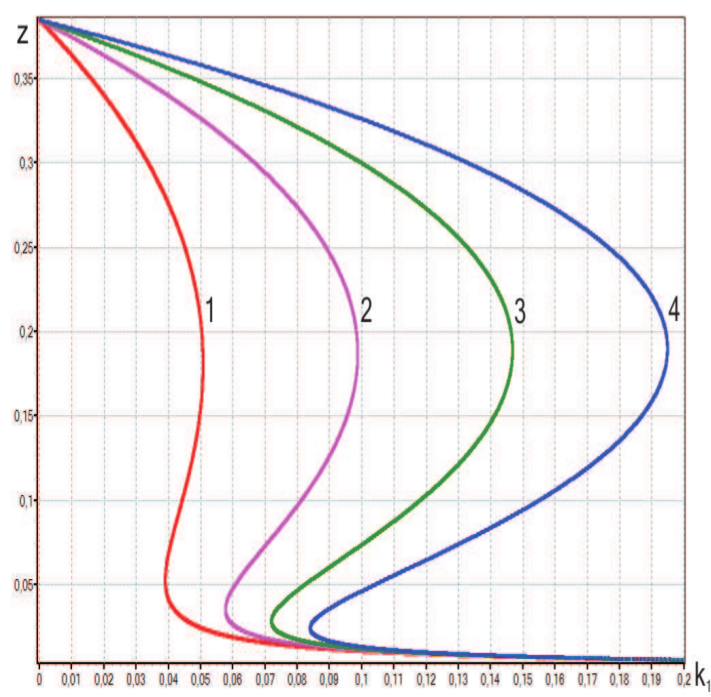

Fig. 1. Parametric relationships $z\left(k_{1}\right)$ for 1) $k_{2}=0.5$;2) 1 ; 3) 1.5 ;4) 2

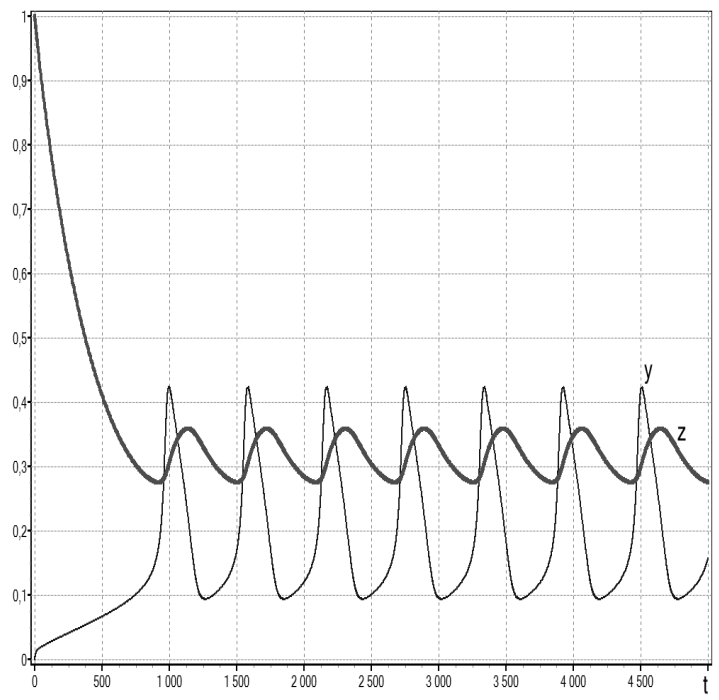

Fig. 3. Solutions of dynamic system (4) corresponding to point 1 for $k_{1}=0.12$ and $k_{-1}=$ 0.01 ,

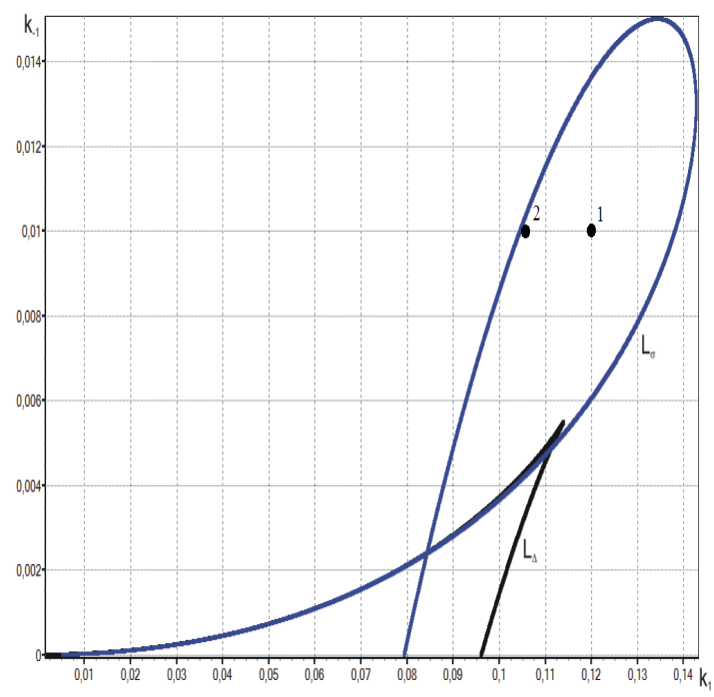

Fig. 2. Mutual arrangement of $L_{\Delta}$ and $L_{\sigma}$ curves in relation to parameters $\left(k_{1}, k_{-1}\right)$

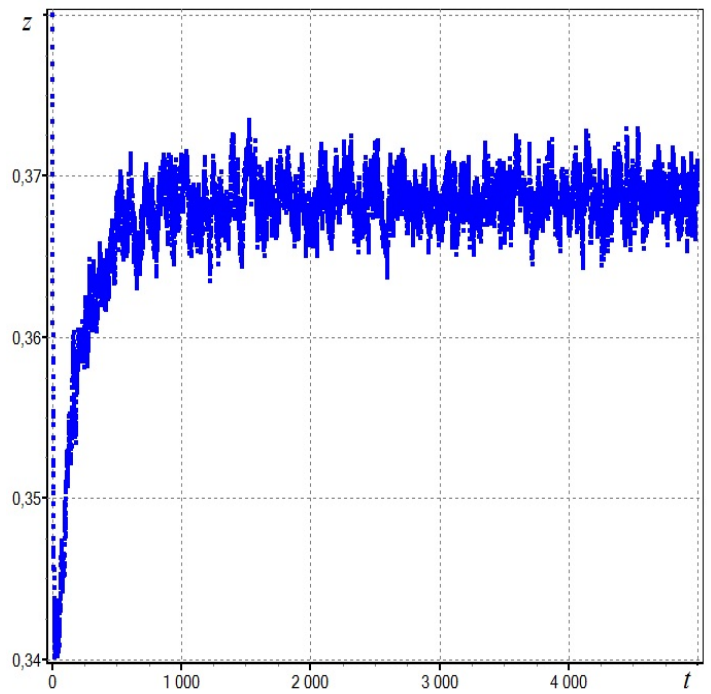

Fig. 4. Chaotization of solutions of dynamic system corresponding to point 2 for $k_{1}=$ 0.105 and $k_{-1}=0.01$

small fluctuations of parameters can lead to the chaotization of system dynamics. Numerical results show that when system parameters change in critical points (for example,on the borders of multiplicity and stability regions) complex oscillations like "chaos" may occur for small random variations in system parameters. 


\section{References}

[1] V.I.Bykov, S.B.Tsybenova, Nonlinear models of chemical kinetics, Moscow, KRASAND, 2011.

[2] V.I.Bykov, S.B.Tsybenova, G.Yablonsky, Chemical complexity via simple models. Modelics, Berlin-Boston, Walter de Gruyter GmbH, 2018.

[3] M.M.Slinko, N.I.Jaeger, Oscillating heterogeneous catalytic systems, Netherlands, Elsevier Science, 1994.

[4] G.S.Yablonskii, V.I.Bykov, A.N.Gorban, V.I.Elokhin, Kinetic models of catalytic reactions, Amsterdam, New-York, Elsevier Science, 1991.

[5] V.I.Bykov, L.S.Trotsenko, Noise-induced kinetic chaos, Russ. J. Phys. Chem., 79(2005), no. 5, 677-680.

\section{Химический "хаос", индуцированный шумом. Базовая кинетическая модель и ее параметрический анализ}

\section{Светлана Б. Цыбенова Валерий И. Быков \\ Людмила С. Троценко}

Институт биохимической физики им. Н. М. Эмануэля РАН Косыгина, 4, Москва, 119334

Россия

$\overline{\text { Предложена базовая модель нестационарного поведения каталитической системы. Показано, что }}$ вблизи границы области параметров, при которых существуют автоколебания, малые флуктуации параметров могут привести к хаотизачии динамики системы в целом.

Ключевые слова: химическая кинетика, кинетическая модель, бифуркачия, шум, хаос, параметрический анализ. 